\title{
NOTES
}

\section{Further Study of Chain End Effect on Surface Mobility in Monodisperse Polystyrene Films}

\author{
Keiji TANAKA ${ }^{\dagger}$, Fumi ArIURA, Toshihiko NAgAmura, and Tisato KAJIYAMA ${ }^{*} \dagger \dagger$ \\ Department of Applied Chemistry, Faculty of Engineering, Kyushu University, Fukuoka 812-8581, Japan \\ *Kyushu University, Fukuoka 812-8581, Japan
}

(Received March 2, 2004; Accepted April 2, 2004; Published June 15, 2004)

KEY WORDS Surface Mobility / Surface Glass Transition / Chain End Effect / Polystyrene /
Lateral Force Microscopy /
[DOI 10.1295/polymj.36.498]

Surfaces of polymeric materials play important roles in many technological applications. ${ }^{1}$ Hence, to design highly functionalized polymeric materials, the systematical understanding of aggregation states and physical properties in the surface region, which are sometimes quite different from the bulk ones, is of pivotal importance as the first benchmark.

In the last decade, surface mobility in polymer films, especially polystyrene (PS), has been extensively explored by many research groups. Consequently, major conclusion emerged is that surface dynamics in PS films is much more enhanced than the internal bulk dynamics, ${ }^{2-15}$ although some contradict arguments are still going on. ${ }^{16-18}$ Even if a notion of enhanced surface dynamics is accepted, it is far from clear for the moment why molecular motion at the PS surface must be activated.

So far, we have examined surface glass transition temperature $\left(T_{\mathrm{g}}^{\mathrm{s}}\right)$ in films of monodisperse $\alpha, \omega$-diamino-terminated PS, which possesses end groups with higher surface free energy than the main chain part. ${ }^{19}$ Since the end groups deeply migrated into the bulk to minimize the interfacial free energy, the difference of glass transition temperature between surface and bulk was not so remarkable as that for PS, synthesized by sec-butyllithium and methanol as an initiator and a terminator, respectively (sec-Bu-PS-H). In the case of the sec-Bu-PS-H, end groups would be partitioned to the surface. ${ }^{2 b, c}$ These results clearly show that the chain end concentration at the surface is closely related to $T_{\mathrm{g}}{ }^{\mathrm{s}}$ value. ${ }^{20-22}$ Hence, further discussion about a chain end effect on surface dynamics should be made so that a whole picture of peculiar surface dynamics can be rationalized. Of course, many factors such as reduced cooperativity, ${ }^{2 \mathrm{2}, 23}$ chain orientation, ${ }^{23}$ and loose entanglement ${ }^{13}$ should be simultaneously stud- ied in addition to the chain end effect.

In general, as a monodisperse PS, sec-Bu-PS-H has been used in most researches related to surface phenomenon. However, sec-Bu-PS-H possesses an asymmetric structure in terms of chain ends, and this would lead to ambiguous understanding to the chain end effect. Hence, in this study, two kinds of PS with symmetric chain ends, $\alpha, \omega$-di-sec-butyl-terminated and $\alpha, \omega$-diproton-terminated polystyrene $\left(\alpha, \omega\right.$-PS $\left(\mathrm{sec}^{-}\right.$ $\mathrm{Bu})_{2}$ and $\left.\alpha, \omega-\mathrm{PS}(\mathrm{H})_{2}\right)$, are synthesized. Our interest is whether $T_{\mathrm{g}}^{\mathrm{s}}$ in films of $\alpha, \omega-\mathrm{PS}(\mathrm{sec}-\mathrm{Bu})_{2}$ and $\alpha, \omega$ $\mathrm{PS}(\mathrm{H})_{2}$ is different, and is to what extent the $T_{\mathrm{g}}{ }^{\mathrm{s}}$ value is dependent on chain end structure, if any.

\section{EXPERIMENTAL}

Figure 1 illustrates synthetic routes of $\alpha, \omega-\mathrm{PS}(\mathrm{sec}$ $\mathrm{Bu})_{2}$ and $\alpha, \omega-\mathrm{PS}(\mathrm{H})_{2} . \alpha, \omega-\mathrm{PS}(\sec -\mathrm{Bu})_{2}, \underline{\mathbf{1}}$, was synthesized by coupling two living styryl anions, initiated by sec-butyllithium, with 1,3-bis(1-phenylethenyl)benzene (MDDPE), 2 . 2 was prepared by Wittig reaction of 1,3-dibenzoylbenzene under the presence of

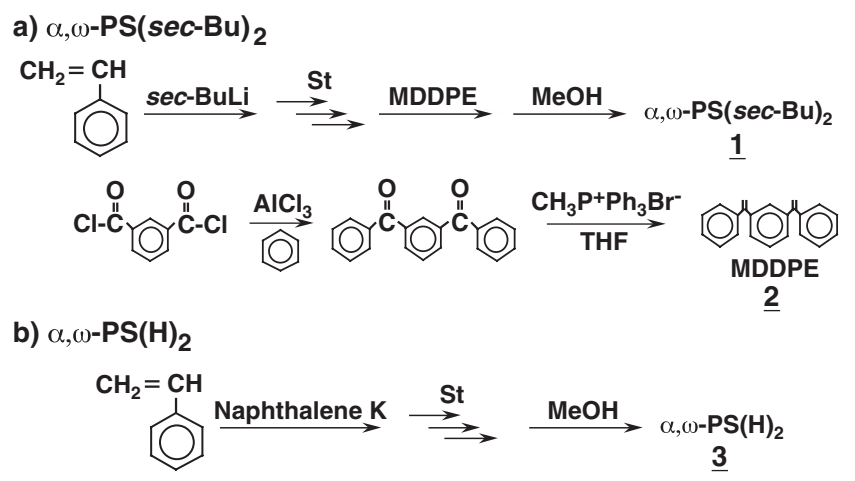

Figure 1. Synthetic routes for (a) $\alpha, \omega-\mathrm{PS}(\mathrm{sec}-\mathrm{Bu})_{2}$ and (b) $\alpha, \omega-\mathrm{PS}(\mathrm{H})_{2}$.

\footnotetext{
${ }^{\dagger}$ To whom correspondence should be addressed (TEL: +81-92-642-3560, Fax: +81-92-651-5606, E-mail: k-tanaka@cstf.kyushu-u.ac.jp).

${ }^{\dagger \dagger}$ To whom correspondence should be addressed (TEL: +81-92-642-2100, E-mail: kajiyama@cstf.kyushu-u.ac.jp).
} 
Table I. Characterization of PS after fractionation

\begin{tabular}{cccc}
\hline \multicolumn{1}{c}{ Polymer } & $M_{\mathrm{n}}$ & $M_{\mathrm{w}} / M_{\mathrm{n}}$ & $T_{\mathrm{g}}{ }^{\mathrm{b}} / \mathrm{K}$ \\
\hline$\alpha, \omega-\mathrm{PS}(\text { sec }-\mathrm{Bu})_{2}$ & $17 \mathrm{k}$ & 1.04 & 370 \\
& $67 \mathrm{k}$ & 1.06 & 372 \\
$\alpha, \omega-\mathrm{PS}(\mathrm{H})_{2}$ & $19 \mathrm{k}$ & 1.04 & 362 \\
& $77 \mathrm{k}$ & 1.06 & 376 \\
\hline
\end{tabular}

triphenylmethylphosphonium bromide. ${ }^{24}$ 1,3-Dibenzoylbenzene was obtained by Friedel Crafts reaction of benzene with isophthaloyl dichloride in the presence of $\mathrm{AlCl}_{3}$, as shown in Figure $1 .{ }^{25}$ Since the coupling reaction was not perfect, the product after the polymerization was fractionated to obtain $\alpha, \omega$ $\mathrm{PS}(\sec -\mathrm{Bu})_{2}$ with high purity. $\alpha, \omega-\mathrm{PS}(\mathrm{H})_{2}, \underline{\mathbf{3}}$, was synthesized using naphthalene potassium and methanol as an initiator and a terminator, respectively.

Table I shows number-average molecular weight $\left(M_{\mathrm{n}}\right)$, molecular weight dispersity $\left(M_{\mathrm{w}} / M_{\mathrm{n}}\right)$, where $M_{\mathrm{w}}$ is weight-average molecular weight, and $T_{\mathrm{g}} \mathrm{b}$ for $\alpha, \omega-\mathrm{PS}(\mathrm{sec}-\mathrm{Bu})_{2}$ and $\alpha, \omega-\mathrm{PS}(\mathrm{H})_{2} . T_{\mathrm{g}}{ }^{\mathrm{b}}$ was measured by differential scanning calorimetry (DSC) under dry nitrogen purge at the heating rate of $10 \mathrm{~K} \cdot \mathrm{min}^{-1}$. $\alpha, \omega$-PS $(\sec -\mathrm{Bu})_{2}$ and $\alpha, \omega-\mathrm{PS}(\mathrm{H})_{2}$ films with the thickness of approximately $200 \mathrm{~nm}$ were spin-coated from toluene solutions onto silicon wafers with a native oxide layer. The thickness was sufficient to avoid any ultrathinning effects on surface dynamics in this $M_{\mathrm{n}}$ range. ${ }^{26}$ To remove residual solvent molecules and eliminate residual stress imposed by the spin coating procedure, the films were dried at $296 \mathrm{~K}$ for more than $24 \mathrm{~h}$, and then, annealed at $423 \mathrm{~K}$ for $24 \mathrm{~h}$ in vacuo. After annealing, the films were cooled down to room temperature at the rate of $0.5 \mathrm{~K} \cdot \mathrm{min}^{-1}$.

Surface relaxation behavior of the films was examined by using an LFM (SPA 300 HV, Seiko Instruments Industry Co., Ltd.) with an SPI 3800 controller. A cantilever used was fabricated from $\mathrm{Si}_{3} \mathrm{~N}_{4}$, of which both sides were uncoated, and possessed the bending spring constant of $0.1 \mathrm{~N} \cdot \mathrm{m}^{-1}$. The normal force onto the cantilever was set to be $10 \mathrm{nN}$ in a repulsive force region. It was pre-confirmed that the sample surface was not damaged by scanning a tip under the current condition. Lateral force was acquired as a function of temperature at the heating rate of $0.4 \mathrm{~K} \cdot \mathrm{min}^{-1}$ under vacuum.

\section{RESULTS AND DISCUSSION}

Frictional behavior of polymeric materials is closely related to their viscoelastic properties. ${ }^{27}$ Hence, it is possible to examine relaxation processes at the polymer surface by using LFM. ${ }^{2,4}$ That is, when mechanical energy at the surface imposed by a sliding tip starts to dissipate due to the release of molecular mo-

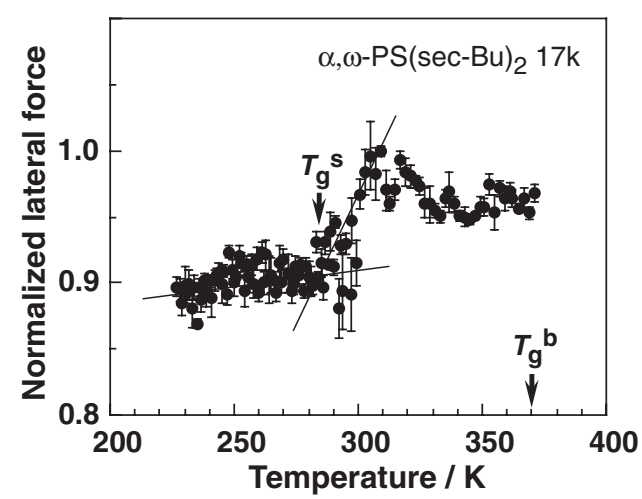

Figure 2. Typical lateral force-temperature curve at the scanning rate of $1 \mu \mathrm{m} \cdot \mathrm{s}^{-1}$. The data is from $\alpha, \omega-\mathrm{PS}(\mathrm{sec}-\mathrm{Bu})_{2}$ with $M_{\mathrm{n}}$ of $17 \mathrm{k}$.

tion, lateral force increases. Thus, it can be postulated that a change of lateral force with measuring temperature is essentially similar to temperature dependence of dynamic loss modulus or loss tangent.

Figure 2 shows a typical temperature dependence of lateral force. The data was obtained from $\alpha, \omega$ $\mathrm{PS}(\text { sec-Bu })_{2}$ with $M_{\mathrm{n}}$ of $17 \mathrm{k}$ under the fixed scanning rate of $1 \mu \mathrm{m} \cdot \mathrm{s}^{-1}$. A lateral force peak was clearly observed at around $310 \mathrm{~K}$. Based on our previous study, ${ }^{2 \mathrm{~d}}$ this peak is assignable to surface $\alpha_{\mathrm{a}}$-relaxation process corresponding to segmental motion, namely, glass-rubber transition at the surface. An onset temperature on the lateral force-temperature curve, that is, the temperature at which the lateral force starts to increase, can be empirically defined as $T_{\mathrm{g}} \mathrm{s} .{ }^{2 \mathrm{~d}, \mathrm{f}}$ In this case, the value was evaluated to be $283 \mathrm{~K}$ on the basis of the intercept of two straight lines, as shown in the figure, and was much lower than the $T_{\mathrm{g}} \mathrm{b}$ of $370 \mathrm{~K}$. This result makes it clear that surface molecular motion is more active than the corresponding bulk motion.

Figure 3 shows the relations of $T_{\mathrm{g}} \mathrm{s}$ and $T_{\mathrm{g}} \mathrm{b}$ to $M_{\mathrm{n}}$ for the $\alpha, \omega-\mathrm{PS}(\mathrm{sec}-\mathrm{Bu})_{2}$ and $\alpha, \omega-\mathrm{PS}(\mathrm{H})_{2}$, denoted by squares and triangles, respectively. To discuss how chain end structure affects $T_{\mathrm{g}}^{\mathrm{s}}$, the data for $s e c-\mathrm{Bu}-$ PS-H with the symbols of small circles are also presented. ${ }^{2 \mathrm{~d}}$ An effect of chain end structure on $T_{\mathrm{g}}{ }^{\mathrm{b}}$ was not significant, and $T_{\mathrm{g}}$ b value monotonically decreased with $M_{\mathrm{n}}$, consistent with the equation established by Fox and Flory. ${ }^{28}$ On the other hand, the $M_{\mathrm{n}}$ dependence of $T_{\mathrm{g}}{ }^{\mathrm{s}}$ seems to be somehow complicated. $T_{\mathrm{g}} \mathrm{s}$ vs. $M_{\mathrm{n}}$ for the sec-Bu-PS-H film was well expressed by a simple power law, $T_{\mathrm{g}}{ }^{\mathrm{s}}=356-$ $K \cdot M_{\mathrm{n}}{ }^{-0.6 \pm 0.03}$ where $K$ is a constant, with the $M_{\mathrm{n}}$ range higher than $10^{3.4}$, as drawn by the thick curve in Figure $3 .^{2 \mathrm{~d}}$ At $M_{\mathrm{n}}$ of approximately $70 \mathrm{k}$ marked by shaded area, $T_{\mathrm{g}} \mathrm{s}$ for all PS films can be directly compared. $T_{\mathrm{g}} \mathrm{s}$ was strongly dependent on what the chain end structure was, and the order was $\alpha, \omega$ - 


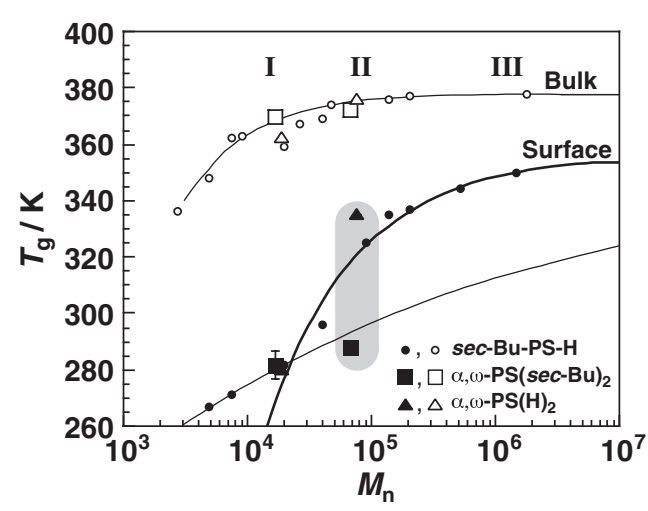

Figure 3. $\quad M_{\mathrm{n}}$ dependences of $T_{\mathrm{g}} \mathrm{s}$ and $T_{\mathrm{g}}{ }^{\mathrm{b}}$ for $\alpha, \omega-\mathrm{PS}(\text { sec-Bu })_{2}$ and $\alpha, \omega-\mathrm{PS}(\mathrm{H})_{2}$. For a comparison, data for sec-Bu-PS-H is also shown. ${ }^{2 \mathrm{~d}}$ See text in detail.

$\mathrm{PS}(\text { sec-Bu })_{2}<\sec$-Bu-PS-H $<\alpha, \omega$-PS $(\mathrm{H})_{2}$. According to prediction for surface free energy $(\gamma)$ based on the notion of group contribution, ${ }^{29}$ the $\gamma$ of a secbutyl group is much smaller than that of a repeating styrene unit. Also, the $\gamma$ of a styrene unit terminated by proton should be slightly lower than that of a repeating one on account of a larger freedom, namely, an entropic contribution, although the energetic difference between the two is trivial. This means that the end groups preferentially segregate at the surface to minimize the interfacial free energy with the air pha$\mathrm{se}^{2 \mathrm{~b}, \mathrm{c}}$ Since the end groups possess the larger freedom, an excess free volume is supposed to be induced at the surface, resulting in enhanced surface mobility. Of course, the depression of $T_{\mathrm{g}}{ }^{\mathrm{s}}$ from the corresponding bulk value is closely related to the extent of surface concentration of chain ends. Taking into account that the $\gamma$ of a sec-butyl group is lower than that of a styrene unit terminated by proton, the aforementioned $T_{\mathrm{g}}{ }^{\mathrm{s}}$ order among the three PS films can be easily understood.

On the other hand, in the case of lower $M_{\mathrm{n}}$ region such as $20 \mathrm{k}$, the chain end effect on $T_{\mathrm{g}}{ }^{\mathrm{s}}$ was not observed at all, as shown in Figure 3. Here, it is noteworthy that the $T_{\mathrm{g}}{ }^{\mathrm{s}}-M_{\mathrm{n}}$ relation for the $s e c-\mathrm{Bu}-\mathrm{PS}-\mathrm{H}$ film was deviated from the power law of $M_{\mathrm{n}}{ }^{-0.6}$. Instead, $T_{\mathrm{g}}{ }^{\mathrm{s}}$ was proportional to $M_{\mathrm{n}}{ }^{-0.13}$, as shown by the thin curve in Figure 3. Invoking that the $M_{\mathrm{n}}$ dependence of glass transition temperature is related to the number density of chain ends, ${ }^{28}$ Figure 3 tells us that in the case of $M_{\mathrm{n}}$ smaller than $20 \mathrm{k}$, the chain end concentration at the surface is not necessarily increased with decreasing $M_{\mathrm{n}}$. A plausible explanation of this is that a chain conformation, of which the both ends are located at the surface, can be hardly realized due to its decreased internal freedom.

The $M_{\mathrm{n}}$ dependence of $T_{\mathrm{g}} \mathrm{s}$ can be roughly divided into three regimes. A clear chain end effect on $T_{\mathrm{g}} \mathrm{s}$ would be observed only for appropriate $M_{\mathrm{n}}$ region, as marked by regime II in Figure 3. In the case of higher $M_{\mathrm{n}}$ region, the dependence will be not experimentally observed due to extremely low chain end concentration although the chain ends preferentially partitioned to the surface. We call this $M_{\mathrm{n}}$ region regime III. In addition, the dependence would not be seen either for lower $M_{\mathrm{n}}$ region because of the above-mentioned reason. Based on Figure 3, it seems reasonable to conclude that chain end chemistry is definitely one of responsible factors for the reduction of glass transition temperature at the film surface. In a sense, however, it is also clear from Figure 3 that the chain end effect cannot fully account for the enhanced mobility in the surface region. Therefore, more systematic studies taking into account other factors should be made in the future.

\section{CONCLUSIONS}

$\alpha, \omega-\mathrm{PS}(\sec -\mathrm{Bu})_{2}$ and $\alpha, \omega-\mathrm{PS}(\mathrm{H})_{2}$ were synthesized by anionic polymerization, and $T_{\mathrm{g}}{ }^{\mathrm{s}}$ in films of $\alpha, \omega$ $\mathrm{PS}(\mathrm{sec}-\mathrm{Bu})_{2}$ and $\alpha, \omega$-PS $(\mathrm{H})_{2}$ was examined by LFM. $T_{\mathrm{g}}{ }^{\mathrm{s}}$ for the films was much smaller than the corresponding bulk value. The results were compared with $T_{\mathrm{g}}$ s for sec-Bu-PS-H. While $T_{\mathrm{g}} \mathrm{s}$ value was strongly dependent on chain end structure in a middle molecular weight region, such was not the case for a lower molecular mass regime. These were explained in terms of chain end concentration at the surface.

Acknowledgment. We are most grateful for fruitful discussion with Prof. Atsushi Takahara, Kyushu University, Japan, and Jeffrey T. Koberstein, Columbia University, U.S.A. And we thank Dr. Kenji Sugiyama, Tokyo Institute of Technology, Japan, for his helpful comments on synthesis of $\alpha, \omega-\mathrm{PS}(\mathrm{sec}-$ $\mathrm{Bu})_{2}$.

\section{REFERENCES}

1. F. Garbassi, M. Morra, and E. Occhiello, "Polymer Surfaces, from Physics to Technology", John Wiley \& Sons, Chichester, U.K., 1994.

2. a) T. Kajiyama, K. Tanaka, I. Ohki, S.-R. Ge, J.-S. Yoon, and A. Takahara, Macromolecules, 27, 7932 (1994).

b) K. Tanaka, A. Taura, S. R. Ge, A. Takahara, and T. Kajiyama, Macromolecules, 29, 3040 (1996).

c) T. Kajiyama, K. Tanaka, and A. Takahara, Macromolecules, 30, 280 (1997).

d) K. Tanaka, A. Takahara, and T. Kajiyama, Macromolecules, 33, 7588 (2000).

e) D. Kawaguchi, K. Tanaka, A. Takahara, and T. Kajiyama, Macromolecules, 36, 1235 (2003).

f) K. Tanaka, K. Hashimoto, T. Kajiyama, and A. Takahara, Langmuir, 19, 6573 (2003).

3. J. L. Keddie, R. A. L. Jones, and R. A. Cory, Europhys. 
Lett., 27, 59 (1994).

4. a) J. A. Hammerschmidt, B. Moasser, W. L. Gladfelter, G. Haugstad, and R. R. Jones, Macromolecules, 29, 8996 (1996).

b) J. A. Hammerschmidt, W. L. Gladfelter, and G. Haugstad, Macromolecules, 32, 3360 (1999).

5. Y. C. Jean, R. Zhang, H. Cao, J. P. Yuan, C. M. Huang, B. Nielsen, and P. Asoka-Kumar, Phys. Rev. B, 56, R8459 (1997).

6. G. B. DeMaggio, W. E. Frieze, D. W. Gidley, M. Zhu, H. A. Hristov, and A. F. Yee, Phys. Rev. Lett., 78, 1524 (1997).

7. a) D. M. G. Agra, A. D. Schwab, J. H. Kim, S. Kumar, and A. Dhinojwala, Europhys. Lett., 51, 655 (2000).

b) A. D. Schwab, D. M. G. Agra, J. H. Kim, S. Kumar, and A. Dhinojwala, Macromolecules, 33, 4903 (2000).

8. a) D. B. Hall and J. M. Torkelson, Macromolecules, 31, 8817 (1998).

b) C. J. Ellison and J. M. Torkelson, Nat. Mater., 2, 695 (2003).

9. V. Zaporojtchenko, T. Strunskus, J. Erichsen, and F. Faupel, Macromolecules, 34, 1125 (2001).

10. T. Kerle, Z. Lin, H. C. Kim, and T. P. Russell, Macromolecules, 34, 3484 (2001).

11. a) W. E. Wallace, D. A. Fischer, K. Efimenko, W. L. Wu, and J. Genzer, Macromolecules, 34, 5081 (2001).

b) W. L. Wu, S. Sambasivan, C. Y. Wan, W. E. Wallace, J. Genzer, and D. A. Fischer, Eur. Phys. J. E, 12, 127 (2003)

12. H. Fischer, Macromolecules, 35, 3592 (2002).

13. V. N. Bliznyuk, H. E. Assender, and G. A. D. Briggs, Macromolecules, 35, 6613 (2002).

14. R. Weber, I. Grotkopp, J. Stettner, M. Tolan, and W. Press, Macromolecules, 36, 9100 (2003).

15. J. H. Teichroeb and J. A. Forrest, Phys. Rev. Lett., 91, 016104 (2003).

16. a) S. R. Ge, Y. Pu, W. Zhang, M. H. Rafailovich, J. Sokolov, M. C. Buenviaje, R. Buckmaster, and R. M. Overney, Phys.
Rev. Lett., 85, 2340 (2000).

b) Y. Pu, M. H. Rafailovich, J. Sokolov, D. Gersappe, T. Peterson, W. L. Wu, and S. A. Schwarz, Phys. Rev. Lett., 87, 206101 (2001).

c) K. Shin, Y. Pu, M. H. Rafailovich, J. Sokolov, O. H. Seeck, S. K. Sinha, M. Tolan, and R. Kolb, Macromolecules, 34, 5620 (2001).

17. R. Weber, K. M. Zimmermann, M. Tolan, J. Stettner, W. Press, O. H. Seeck, J. Erichsen, V. Zaporojtchenko, T. Strunskus, and F. Faupel, Phys. Rev. E, 64, 061508 (2001).

18. H. Kim, A. Ruhm, L. B. Lurio, J. K. Basu, J. Lai, D. Lumma, S. G. J. Mochrie, and S. K. Sinha, Phys. Rev. Lett., 90, 068302 (2003).

19. a) K. Tanaka, X. Jiang, K. Nakamura, A. Takahara, T. Kajiyama, T. Ishizone, A. Hirao, and S. Nakahama, Macromolecules, 31, 5148 (1998).

b) N. Satomi, K. Tanaka, A. Takahara, T. Kajiyama, T. Ishizone, and S. Nakahama, Macromolecules, 34, 8761 (2001).

20. A. M. Mayes, Macromolecules, 27, 3114 (1994).

21. J. A. Forrest, J. Mattsson, and L. Borjesson, Eur. Phys. J. E, 8, 129 (2002).

22. N. Tokita, M. Hirabayashi, C. Azuma, and T. Dotera, J. Chem. Phys., 120, 496 (2004).

23. K. L. Ngai, A. K. Rizos, and D. J. Plazek, J. Non-Cryst. Solids, 235, 435 (1998).

24. G. G. H. Schulz and H. Höcker, Makromol. Chem., 178, 2589 (1977).

25. R. J. Anderson and C. A. Henrick, J. Am. Chem. Soc., 97, 4327 (1975).

26. K. Akabori, K. Tanaka, T. Kajiyama, and A. Takahara, Macromolecules, 36, 4937 (2003).

27. K. Minato and T. Takemura, Jpn. J. Appl. Phys., 6, 719 (1967).

28. T. Fox and P. Flory, J. Polym. Sci., 14, 315 (1954).

29. C. Jalbert, J. T. Koberstein, A. Hariharan, and S. K. Kumar, Macromolecules, 30, 4481 (1997). 